\title{
IMPRESSÕES E ARQUIVOS: NOTAS SOBRE-VIDA, LITERATURA E VIDA LITERÁRIA EM QUARTO DE DESPEJO, DE CAROLINA MARIA DE JESUS
}

\author{
Impressions and archives: notes on survival, literature and literary life [literary \\ living] in Quarto de despejo, by Carolina Maria de Jesus
}

\author{
Gustavo Tanus \\ https://orcid.org/0000-0002-5696-7187 (] \\ Universidade Federal do Rio Grande do Norte, Programa de Pós-Graduação \\ em Estudos da Linguagem, Natal, RN, Brasil. \\ CEP 59078-970 - posletrasufrn@gmail.com
}

\begin{abstract}
Resumo: Neste ensaio, propomos uma crítica sobre arquivos literários, refletindo, sobretudo o arquivo da Carolina Maria de Jesus. Nossa motivação primeira advém da leitura de Quarto de despejo (1960), da autora; livro que é sua estreia na literatura e contemplou seus cadernos de memórias, edição que teve, numa recepção de primeira hora, foco documental nos aspectos do ambiente social no qual ela vivia e sobre o qual ela registrara suas memórias. Passado esse interesse sobre os lugares periféricos, relacionando também a uma dita tradição literária brasileira que não recebe bem a escrita diarística que não a de um sujeito mesmo, a autora não conseguira, em vida, um lugar estável e de reconhecimento pela qualidade de sua escrita, na profissão de escritora. Cogitamos refletir sobre o arquivo da escritora, pensando o trânsito performático rumo às instituições custodiadoras, estas que são, sobretudo, de conservação de arquivos de escritores da tradição; deslocamento do texto literário dela, lido antes como documental, para os documentos de acervo, que são literatura em potência de ser editada e/ou reeditada, portanto, recebida e possivelmente repensada em outras críticas. Observamos o caminho desde o arquivo que é "cérebro do poeta", às suas "impressões" literárias, a que o livro aqui analisado é bastante representativo, reforçadas as impressões sobre a vida, a literatura, a vida literária e a "sobrevida", esta em senso derridiano, ao que conectaremos à perspectiva de "escrevivência de nós", ato/termo elaborado pela escritora crítica Conceição Evaristo. Para este ensaio, convocamos, além dela, Foucault, Derrida, Bhabha, sem os quais não poderíamos questionar as formas e os conteúdos dos arquivos da colonialidade, estes também contribuidores para a formação da ideia de nação, a qual está representada nos arquivos da nação, seja pela presença do gênio, do herói, seja pela ausência do que é posto como popular, como antagonista, como marginal.
\end{abstract}

Palavras-chave: Crítica literária; Literatura brasileira; Arquivo literário; Arquivo afro-brasileiro. Carolina Maria de Jesus.

Abstract: In this essay, we propose a critique of literary archives, reflecting, above all, on the archive of Carolina Maria de Jesus. Our first motivation comes from reading the author's Quarto de despejo (1960); book that is her debut in literature, and contemplated her notebooks of memories, an edition that had, in a first hour reception, a documentary focus, in the aspects of the social environment in which she lived, and about which she had recorded her memories. Regarding the release of this book, that interest in peripheral places has passed. In addition of this, a so-called Brazilian literary tradition that does badly receive a memoir writing, that depend of the author, Carolina had not managed, in life, to have a stable place, and to be recognized for the quality of her writing, in the 
profession of writer. We consider reflecting on the writer's archive, thinking about the performance path towards custodian institutions, which are, above all, for the conservation of archives of traditional writers; displacement of her literary text, previously read as documentary, for the collection documents, which are potentially literature to be edited and / or reedited, therefore, received and possibly rethought in other criticisms. We observe the path from the archive that is "the poet's brain", to her literary "impressions", to which the book analyzed here is quite representative, reinforced the impressions about life, literature, literary life and "survival", this in a Deridian sense, to which we will connect to the perspective of "livature", an act / term elaborated by the critical writer Conceição Evaristo. For this essay, we call, additionally, Foucault, Derrida, Bhabha, without whom we would not be able to question the forms and contents of the archives of coloniality, these also contributing to the formation of the idea of nation, which is represented in the nation's archives, either by the presence of genius, the hero, or by the absence of what is considered popular, as antagonist, as marginal.

Keywords: Literary criticism; Brazilian literature; Literary archive; African-Brazilian archive; Carolina Maria de Jesus.

"Eu sou poetisa, senhor Osvaldo, e o cérebro do poeta é um arquivo. Por isso, o senhor deveria considerar minhas impressões". (Carolina Maria de Jesus).

Escrever uma crítica de um texto que é muito conhecido, bastante lido, cada vez mais, desde a sua primeira edição, há mais de 60 anos, é espinhoso. As dificuldades são inúmeras tanto porque muita coisa importante e interessante foi ou tem sido escrita desde então. Isso nos movimenta a tentar pensar um modo de ler/ver a obra dentro deste contexto com que as leituras vieram sendo feitas, tentando pensar as "impressões da poeta". Só em relação ao volume de críticas, a título de curiosidade, em levantamento realizado no Banco de Teses e Dissertações do Instituto Brasileiro de Informação em Ciência e Tecnologia (IBICT), o total de pesquisas que estudaram a obra de Carolina Maria de Jesus, recuperados nesse arquivo, desde 2003 até 2020, foram 164, sendo cerca $90 \%$ destes trabalhos produzidos na década 2010-2020. Ainda, se consideramos apenas o livro Quarto de despejo, são 42 ocorrências, nesta década. Em relação ao caráter temático dessas pesquisas, percebemos, de modo geral, que elas têm estudado, desde crítica textual, passando pela crítica biográfica, até, mais ultimamente, a crítica genética, esta convalidada pelo acesso aos originais (tanto os manuscritos à mão, quanto seus microfilmes). Em tais trabalhos, estudam-se, entre outras direções, a autoria, a condição de periférica (posta à escritora, ao gênero textual, e à literatura produzida); estuda-se interseccionalidade das identidades sociais (gênero, raça), e dos sistemas referentes à opressão, à dominação, à discriminação, ao racismo etc.

De nossa parte, ainda que não tivéssemos estudado no mestrado ou no doutorado a obra de Carolina Maria de Jesus, observamos as discussões sobre o acervo da escritora, em seus caminhos de dispersão pelos acervos literários brasileiros; a chegar, em trânsito entre o papel dos cadernos, às imagens com a digitalização desses microfilmes, estes que foram doados ao Acervo de Escritores Mineiros (AEM/UFMG), na condição de um arquivo virtual (SOUZA, 2017). Na época da doação, estávamos envolvidos na identificação e organização dos documentos do Acervo do poeta Adão Ventura, acervo cuja incorporação, 
além da conservação, guarda e disponibilização dos documentos - sobre-vida, literatura e vida literária - desse escritor, realizara uma operação dupla de um arquivo dentro do arquivo, por conta das clipagens de notícias que o poeta realizara sobre a questão racial brasileira, entre racismos e preconceitos; o que conserva em arquivo, dentro de uma instituição oficial, o que a sociedade brasileira (e seus tantos outros arquivos ${ }^{1}$ ) insistem ser possível esconder: o passado escravista e suas formas de continuidade no nosso presente.

As diferentes formas de acesso aos originais da escritora contribui para o fortalecimento de outras críticas (lembramos, aqui, entre tantos outros, do trabalho realizado pela pesquisadora Aline Alves Arruda, em sua tese, defendida em 2015, em que estudou o romance inédito, Dr. Sílvio, propondo uma edição crítica para ele), fomenta projetos de edição (como, por exemplo, a publicação recente dos contos inéditos no volume Onde estaes felicidade?, organizado pelas pesquisadoras Dinha e Raffaella Fernandez ${ }^{2}$, 2014) e de reedição (consta que a obra completa sairá, em 2021, pela editora Companhia das Letras, sob coordenação de Vera Eunice de Jesus, filha da autora).

Carolina Maria de Jesus, Bitita, seu apelido de infância, nasceu em 1914, início da Primeira Guerra Mundial, na cidade mineira de Sacramento. Neta de ex-escravizados, teve, na figura do avô, o senhor Benedito da Silva (o "Sócrates africano", como ela disse em um conto $^{3}$ ), referencial de figura masculina. Ele e Cota, mãe de Bitita, foram os responsáveis por sua criação, ensinando-lhe valores familiares e culturais. Após um episódio de racismo, em que ela fora acusada por um furto, tendo apanhado e sido presa, ela decidiu mudar-se para a cidade de São Paulo (FARIAS, 2018; LEVINE; MEIHY, 1995). Na cidade de São Paulo, ela trabalhou como empregada doméstica para a alta burguesia, onde teve acesso aos livros e às bibliotecas dessa gente. Segundo José Carlos de Jesus, o segundo filho da autora, ali ela teve um tipo de experiência, que relaciona a aprendizagem com seus mais velhos e sua relação com os mais novos, numa lição a ser aprendida e nunca esquecida, geradora de um sentimento importante para a luta contra as desigualdades: "Minha mãe teve um tipo de alta espiritualidade, orgulho e, por isso, ela nunca se curvou aos patrões.

\footnotetext{
${ }_{1}^{1}$ Recordemos o despacho de Rui Barbosa, que ordena a incineração de registros documentais da escravidão. À época, houve movimentação contrária a essa ordem, pelo fato de os documentos serem parte da história, que tentavam apagar, como se isso fosse possível, porque, como disse a personagem machadiana, Conselheiro Ayres, em seu diário, no dia 13 de maio de 1888: "Embora queimemos todas as leis, decretos e avisos, não poderemos acabar com os atos particulares, escrituras e inventários, nem apagar a instituição da história, ou até da poesia." (ASSIS, 1997, p. 1117).

2 Estudiosa em cuja tese trabalhou, a partir da crítica genética, os manuscritos de Carolina Maria de Jesus, no sentido de observar os processos de criação da escritora.

3 Originalmente publicado em 1994 no livro Cinderela negra: a saga de Carolina Maria de Jesus, pesquisa de Robert Levine e José Carlos Sebe Bom Meihy; foi republicado, em 2014, no portal literafro, acessível pelo endereço eletrônico: http://www.letras.ufmg.br/literafro/24-textos-das-autoras/65-carolina-maria-de-jesus-osocrates-africano.
} 
Aprendi com ela esta lição: pobreza não significa inferioridade"4 (JESUS, 1995, p. 121, tradução nossa).

A escritora publicou, diários, autobiografias, poemas, canções, provérbios e romances, estes inéditos, em vida, os livros Quarto de despejo: diário de uma favelada (1960) (Memórias); Casa de alvenaria: diário de uma ex-favelada (1961); Pedaços da fome (1963); e Provérbios (1963); além de sua obra póstuma Diário de Bitita (1986); Meu estranho diário (1996); Antologia pessoal (1996); Onde estaes felicidade? (2014); Meu sonho é escrever... contos inéditos e outros escritos (2018). Segundo a pesquisa de Flávia de Oliveira (2020), das obras de autoria de escritoras negras que se encontram nos acervos das bibliotecas públicas estaduais brasileiras (14 delas que disponibilizam o acesso online ao catálogo), o livro Quarto de despejo... integra o acervo em 11 delas, sendo a autora mais presente nos acervos dessas bibliotecas, e esta, a obra a mais frequente; um importante legado para as gerações brasileiras.

Para este ensaio orientamo-nos pela questão posta por Conceição Evaristo: "O que levaria determinadas mulheres, nascidas e criadas em ambientes não letrados, e quando muito, semi-alfabetizados, a romperem com a passividade da leitura e buscarem o movimento da escrita?" (EVARISTO, 2007, p. 20), a qual ela mesmo contesta dizendo que "o ato de ler oferece a apreensão do mundo, o de escrever ultrapassa os limites de uma percepção da vida" (EVARISTO, 2007, p. 21). Estes atos, que motivaram a vida de Carolina, como ela mesma disse reiteradamente em seus livros, são o ponto crucial de uma experiência que a permitiu escrever textos que são importantes e constroem sua obra. Em reflexão metalinguística, a autora justifica (JESUS, 1960, p. 25): "Há tempos que eu pretendia fazer o meu diário. Mas eu pensava que não tinha valor e achei que era perder tempo. ...Eu fiz uma reforma em mim. Quero tratar as pessoas que eu conheço com mais atenção. Quero enviar um sorriso amável as crianças e aos operários. (2 de maio de 1958)".

Algumas das questões que podemos colocar, num primeiro momento, dizem respeito à modificação da recepção do texto, que partiu da esfera de um interesse sociológico, no momento de sua edição e de seu lançamento, numa espécie de fetiche que as ditas "elites" possuíam e possuem sobre narrativas periféricas (tal interesse é o ponto da seleção de trechos para a edição do diário, realizada pelo jornalista Audálio Dantas), convivendo com uma outra recepção que conhece o texto e se reconhece nele, produzindo novas formas de se relacionar com seus con-textos, superando a simples crítica impressionista, sobretudo, porque as posições são marcas de criação de campos recepcional, artístico, político... Isso tem modificado o jogo literário sobre a obra de Carolina, que passou a ter outras recepções na Academia, lembrando o que disse Acauam Oliveira (2019), ao falar da produção dos

\footnotetext{
4 "My mother had a kind of high spirituality, pride, and because of this she never kowtowed to her bosses. I learned this lesson from her: poverty does not mean inferiority." (JESUS, 1995, p. 121).
} 
Racionais MC's, mas que toca pensar os estudos sobre alteridades periféricas, a universidade produz um tipo de saber que, olhando por sua relevância social, tem assumido frequentemente "um caráter bacharelesco e ornamental, como uma espécie de enfeite de luxo, justamente por ser produzido a partir de uma fratura social que a ela própria interessa perpetuar." (OLIVEIRA, 2019, n.p.); ao que podemos contrapor com as maneiras de questionar as fraturas, em discussão e apresentação de modos de resolvê-las, destacados os inúmeros trabalhos das pesquisadoras da obra de Carolina, como os acima apontados.

As primeiras vistas do livro Quarto de despejo..., em sua época de lançamento, primeira edição, de 10 mil exemplares rapidamente vendidos, sucesso tamanho que urgiu a reimpressão em vários lotes, tendo vendido, no mesmo ano de seu lançamento, isto é, em 1960, cerca de 100 mil exemplares. Não é possível confirmar que esse primeiro interesse se relaciona indubitavelmente ao desejo sociológico pela narrativa (mesmo que, naquele momento, conforme disse Meihy, "a pobreza urbana deixava de ser tema periférico na reflexão sociológica" (2014, p. 1), apesar das movimentações em torno da edição e publicidade da obra tenham direcionado leitores para uma "leitura sociológica da obra" (PERPÉTUA, 2000, p. 21 apud MIRANDA, 2013, p. 44); porém, pelo decorrer dos acontecimentos em torno da escritora em relação às suas obras posteriores, e as movimentações do mercado para o ostracismo, também não seria impossível relacionar a isso. Como Robert M. Levine e José Carlos Sebe Bom Meihy (1995) disseram, pouquíssimo tempo depois de ela ter se tornado figura pública internacional pelo livro Quarto de despejo..., a crítica pública sobre sua personalidade, sobre seu comportamento e sua imagem, superaram a observação de suas ideias; tendo sido, inclusive, insinuado que ela e sua obra não mereciam elogio, ignorando, pois, as tantas questões levantadas e trabalhadas por ela em seus escritos, como: "a fome, o desemprego, o racismo, as dificuldades enfrentadas pelas mulheres, a rigidez do sistema de classes no Brasil, as degradações sofridas pelos pobres" (LEVINE; MEIHY, 1995, p. 62, tradução nossa).

A essas condições de recepção e circulação dos textos de autoria negra, periférica, dentro da Literatura Brasileira, como território de con-validação do considerado "modelar" - leia-se homem, branco, com posses, sudestino, em profissões consideradas de poder (DALCASTAGNÈ, 2012) -, somam-se a outras como o gênero textual do diário; isto é, não apenas o gênero em si, mas o gênero da autoria, uma mulher que escreve diários. A professora e estudiosa Elzira Perpétua (2014) nos diz que há que se levar em conta, ainda, dessas escritas de cunho pessoal, a distinção que estudiosos do gênero estabelecem entre os termos "memória, autobiografia, diário, autorretrato (e, mais recentemente a correspondência)" (PERPÉTUA, 2014b, p. 256). Destes, o diário seria menos literário, pois, diferente das memórias e das autobiografias, o intervalo entre o que se viveu e o que se escreverá é pequeno (PERPÉTUA, 2014b). Adiciona-se a isto o questionamento sobre as 
memórias e quem pode tê-las, escrevê-las? Isaías Caminha escrevera, pois - em escrevivência, segundo Conceição Evaristo (2020), em memória, reminiscências, suas recordações.

Bom Meihy (2014), em entrevista, nos disse que "Há ainda mais um aspecto a ser revelado em favor da aceitação dos diários. Afora grandes figuras do universo da política e da cultura, tipos sempre masculinos, a produção literária brasileira virava as costas às biografias e diários". (2014b, p. 3). Elzira Perpétua (2014b) colocara essa mesma questão, com relação aos "volumes das Memórias, de Pedro Nava, ou à Infância, de Graciliano Ramos, em pertencimento à literatura, à alta literatura, enquanto o mesmo não se aplica, pelo menos não como unanimidade, a Cidade de Deus, de Paulo Lins, ou o Quarto de despejo, de Carolina Maria de Jesus". (2014b, p. 255).

Se as biografias podem ser pensadas entre mimesis e vidas imaginárias, o que lhes é próprio é o que Francois Dosse (2007) chamou de indistinção epistemológica, isso porque o gênero mescla certa erudição, criatividade literária, e intuição psicológica; no caso dos diários, gênero literário considerado menor, por uma crítica conservadora, eles são, por si, complexos, porque envolvem uma escrita íntima, de relatos episódicos, meio crônicas. Se estas foram, pela crítica, lidas como lugar geométrico entre a poesia e a prosa; poderíamos pensar, dos diários, como num proposto lugar geométrico (em alguns casos, em divisão igualitária, em outras não) entre o público e o privado. As fronteiras entre casa e mundo tem, segundo Homi K. Bhabha (2013), se tornado confusas, e, de modo estranho, o público e o privado, se tornaram parte um do outro; vejamos que não se trata, pois, de estar em um ou outro lado, mas em um lugar (estado?) de fronteira. Qual é o efeito disso em um gênero literário que já porta a qualidade de poder ser revelador das zonas fronteiriças, dele mesmo, isto é, do próprio gênero, também do relato em si, daquilo que leva como texto, oscilando entre segredo guardado e a intenção (in-tensão) de sua revelação?

A experiência literária de Carolina da obra que é foco desta análise foi feita sob essa forma do diário, uma escrita de si, que poderia ser relacionada à "escrevivência de nós", uma ação, como conceituado pela criadora Conceição Evaristo (2020), que é um "ato de escrita das mulheres negras, como uma ação que pretende borrar, desfazer uma imagem do passado, em que o corpo-voz de mulheres negras escravizadas tinha sua potência de emissão também sob o controle dos escravocratas, homens, mulheres e até crianças". (2020, p. 30).

Como leitor, crítico, pesquisador de arquivos, que se preocupa com as relações entre vida, literatura e vida literária, também percebidas nos arquivos literários, nosso objetivo é transitar das primeiras experiências de leitura, perseguindo um caminho de múltiplas camadas de leitura, percebendo os enredamentos e alinhavos, da obra, em seus movimentos e caminhos até os leitores, seja pela referida modificação da crítica e da 
recepção. Motivamo-nos pela própria afirmação da narradora, epígrafe deste ensaio, em um dos tantos momentos em que ela tratou sobre a face da escritora, face da poeta, tanto em construção, quanto em autoafirmação, em que a autora afirma que a memória da poeta, como um arquivo, guarda, conserva, aquilo que será a matéria para a atividade literária, em suas “impressões” (JESUS apud PERPÉTUA, 2014a, p. 306).

De maneira diferente a construída pelo deslocamento do arquivo de Adão Ventura, o acervo de Carolina, uma escritora, cuja obra literária memorialística foi quase sempre reduzida ao registro sociológico de um espaço periférico, portanto, documental, adentra o espaço dos arquivos como documentos efetivos, formados por seus cadernos de textos literários (originais reais e virtualizados), em diversos gêneros, em um acervo literário conservado de escritores da tradição. É com certa ironia que a literatura de Carolina, tratada, em um modo conservador, como documental, toma lugar nos acervos, agora sim como documentos (que são os originais de seus textos literários) estes que compõem seu arquivo literário. Tal ironia se completa pela consciência dessa oscilação intergenérica (tanto da questão de validade e aceitação das memórias de escritoras frente às memórias literárias dos escritores; quanto do texto literário - inédito e editado, porém em sua forma primeira), que facilitam a instauração, nos acervos de escritores, da percepção da perspectivação do jogo de construção da memória pela atividade de suplementaridade, essa adição descentradora.

Em geral, os arquivos de escritores e escritoras, como todo arquivo pessoal, nos mostram um esforço de constituição de uma memória, que não são somente a constituição de provas de existência ou do reflexo do exercício de cidadania, mas, como arquivos de poetas, demonstram, sobretudo, a investida autobiográfica em criar/manter uma imagem de si, do sujeito como autor/autora, em seus modos de ler/escrever a cultura, suas experiências de linguagem. Nesse sentido, sem reduzir a experiência literária ao arquivo propriamente dito, mas reforçando o caráter de observar/refletir/coletar/transformar experiências cotidianas em linguagem literária, cogitamos pensar a oscilação, do deslocamento, do trânsito dos textos literários de Carolina (como documentos de seu arquivo pessoal) rumo à instituição de memória, em recomposição ao que o professor Reinaldo Marques (2014) tratou de "arquivo literário", este que figura no limiar entre o público e o privado.

Os arquivos, de modo geral, são dedicados à celebração do mesmo sujeito. No caso de arquivos literários, vemos fortemente a presença de escritores, sujeitos brancos, ligados a uma tradição de poder político e econômico; expressando uma ideia tanto de panteão oficial de heróis (vejamos que os sujeitos negros e as mulheres são alteridades dentro desse sistema; e interseccionam-se ser mulher, negra), quanto daquilo que sentimos sobre o que nos ensinaram as instituições pedagógicas e de memória, ser o nosso "legado", antes forjados nas metanarrativas nacionais, de constituição do país modelo, de um povo modelar, cujas formas fixas e estáveis de uma narrativa, estavam baseada em teorias ocidentais de um "tempo horizontal, homogêneo e vazio" (BHABHA, 2013, p. 247). Vale 
lembrar que estas narrativas da nação, as quais podiam ser compostas pelos arquivos coloniais (tanto pelos documentos arquivado nas casas de guarda, quanto pelos que grassam imaginário), tendem a conservar um já posto, contributivo para o reforço de imagens cristalizadas, reiteradas em estereótipos sobre as alteridades ${ }^{5}$, fabricados na ambivalência do prazer/repulsa, fobia/fetiche, fascínio/medo; e a questão, segundo Bhabha (2013), relaciona-se ao modo de pronunciamento contraditório, que haverá sempre de se reinscrever nesse modo ambivalente em relação aos poderes tanto do colonizador quanto do colonizado, a fim de que não se revelasse a incompatibilidade entre império e nação.

No caso das alteridades, isto é, das minorias étnico-raciais, elas adentravam os arquivos (quais arquivos?), por vezes sem individualidade, em outras, sem identidade, como informações de um grupo que não corresponderia ao considerado modelar, e a intenção era no sentido de reforçar informações sobre o Outro, para sua dominação. Primeiro, sob a guarda dos gabinetes de curiosidades (os quais não foram suplantados para as Américas como um lugar, porém vieram como ação e pecha adjetiva), valendo pelo fetiche pelo exótico (senso comum: ex-optico, fora da óptica, do olhar do colonizador); depois, aos arquivos da modernidade (arquivos coloniais), constituídos para alocar as diferenças, ordenadas, classificadas, sob a linguagem taxonômica, isto é, controladas. De uma outra visada, ao entendermos os arquivos sob a lente foucaultiana (2008), de um sistema, um jogo de regras que, numa cultura determinam o aparecimento e o desaparecimento dos enunciados, sua permanência e seu apagamento; deste modo metafórico, a este jogo de regras criadas para a exploração, a segregação e o aniquilamento, dentro da leitura da crítica da "razão negra", proposta pelo filósofo camaronês Achille Mbembe (2014), que forneceram, também sob a "forma de conhecimento" que são os estereótipos (BHABHA, 2013), justificativas para a contenção do desejo de liberdade dos sujeitos escravizados, contendo também os chamados "motins" na história brasileira: conjuração; as revoluções de caráter popular - a revolução, nas áreas colonizadas; forjando/fomentando o imaginário colonial, esse grande arquivo de/para dominação.

Como dissemos acima, em 2014, foi incorporado o arquivo de Carolina ao AEM, que consiste na microfilmagem de seus cadernos. Essa presença virtual, já que são os microfilmes, evidencia os jogos entre ausência/presença; visível/invisível, que pode ser pensado pela ideia de "sobrevida". Na maneira como Bhabha leu (2013, p. 356), essa sobrevida seria análoga ao modo de relacionar ao tempo benjaminiano da tradução, um ato durativo nos interstícios, que des-normatiza a norma, entre a vida e a literatura, num potencial de encontro com o intraduzível. Pensado como conceito derridiano para o arquivo, ela, a "sobrevida", foi pensada pelo escorregamento de significação do termo em francês (que, nessa língua, acumula a acepção de sobreviver e de reviver). Sobrevida, para Derrida,

\footnotetext{
${ }^{5}$ Os estereótipos, segundo Bhabha (2013), são uma forma de conhecimento e identificação, cuja estruturação depende de algo que já foi dado, que está no lugar e o que será repetido, reiterado. Nessa ambivalência, porta um excesso que não podendo ser provado empiricamente, porque não é de fato uma verdade, há de ser renovado, sempre, em novas repetições, sua condição de existência. (BHABHA, 2013).
} 
tem a ver com um triunfo da vida, e sobrevivência não teria mais uma relação com a morte e o retorno de um fantasma, mas um excesso de vida que resistiria ao aniquilamento (2001): "[...] [o] sentido não se acresce ao fato de viver e ao de morrer. Ela [a sobrevida] é originária: a vida é sobrevida. Sobreviver no sentido corrente quer dizer continuar a viver, mas também viver depois da morte" (DERRIDA, 2004, p. 13). Isso, pois, que revive quem da morte volta. Vivo quase morto. São conceitos que ele pensou para trabalhar a noção de rastro e espectral, utilizados para ler o arquivo, para realizar, por exemplo, crítica biográfica entre outras. Paulo Freire (2016), em seu Pedagogia do Oprimido diz algo que pode ser referido a esse conceito/condição, quando atribuídos aos humanos: "Não há vida sem morte, como não há morte sem vida, mas há também uma 'morte em vida'. $E$ a 'morte em vida' é exatamente a vida proibida de ser vida" (FREIRE, 2016, p. 264).

Porém, se tal condição é uma dimensão estrutural importante para a condição de sobrevivência de temas/documentos, para os humanos a sobrevida é algo que não possibilita viver para além da tragédia cotidiana (que se alonga intergerações). Como disse T. C. Silva (2020), em sua fala sobre movimento quilombola:

[...] Começo a mudar, dentro da minha alma, a compreensão do nosso direito à vida não estamos aqui para sobreviver. [...] A sobrevivência é a tragédia. Eu não posso entender que a nossa vida seja uma tragédia. Não posso aceitar isso. Quem disse que a nossa vida tem que ser uma tragédia, para nos transformar em sobreviventes? (2020, 5'22"'-5'42").

Isso significa pensar análoga e metaforicamente que, ao atravessarmos a rua, de repente um automóvel vem desgovernado para cima de nós, instintivamente damos um passo, às vezes para frente, em outras para trás, e o carro atravessa, tirando uma fina, enfim, sobrevivemos. Esse automóvel, no caso das minorias étnico-raciais, representa e performa as formas de racismo (e não está desgovernado, haja vista as tantas iniciativas, vistas no decorrer da história, para manter sua estruturação, mantê-lo em funcionamento). Para onde os sujeitos das minorias étnicas se direcionam, esse veículo se desloca, com o fito de atropelá-los. Nesse sentido, a sobrevivência não é ação singular, para a qual se pode despender um enorme volume de energia, e depois descansar, recuperando essas energias. Há que estar vigilante, todo o tempo. Viver desta forma se não nos enlouquece, aumenta a resistência contrária a seus atravessamentos; porque reduz sua vida a sobreviver. "Sombras de gente, homens, mulheres, [meninas e] meninos desesperançados e submetidos a uma permanente 'guerra invisível', em que o pouco de vida que lhes resta vai sendo devorado [...]" (FREIRE, 2016, p. 264).

Já para os arquivos, a sobrevida não é só positiva, porque é uma vivência pos-mortem da criadora do arquivo, mas também porque, no sentido de o sujeito, humano, apesar de ter passado, pode estar ali, vivo em sua potência sempre presente de poder, também por uma iterabilidade técnica, que possibilita ser re-lido/re-vivido. Assim, o deslocamento do arquivo de Carolina para o AEM, um dos lugares (institucionais, oficiais) poderia ser pensado em um outro lugar onde a escritora poderá viver, sobreviver, reviver, com seus 
documentos de escrita, textos como originais éditos e inéditos, que trataram sobre a vida, sobre a sobrevida, mas também sobre a literatura e a vida literária (a criação literária, que Carolina pensa sob a metáfora do arquivo e das impressões; e seus esforços para construir sua identidade autoral). Além desse novo lugar, o melhor lugar em que uma obra sempre poderá re-viver, que, perdoem o clichê, é nas/pelas leituras, nas/pelas leitoras.

$\mathrm{O}$ arquivo de Carolina realiza, pois, um movimento duplo concomitante de se fazer presente, visível, num ambiente excludente - este não só porque exclui como operação ativa -, re-existente; seu acervo ao mesmo tempo permite (in)surgir, no interior da instituição de memória, questionamentos acerca das in-visibilidades (TANUS, 2019). A modificação se deu não apenas por conta da natureza documental (digital), nem somente pela maneira de acumulação e formação do acervo, que é essencial para entender as dinâmicas das formas de opressões, mas, também, por conta do deslocamento provocado pela integração do arquivo de Carolina Maria de Jesus ao acervo literário de escritores e escritoras ligados à tradição literária. Com isso, podemos pensar, como as "minorias" foram e são "representadas" dentro de narrativas totalizantes (que os arquivos, mas não apenas eles, geralmente representam ou reforçam), apontando a necessidade de desafiar e desmantelar tais narrativas, em narrativas que são possibilitadas e construídas pelos escritos da poeta, tanto no arquivo de impressões, conforme definido pela própria escritora, quanto pelos arquivos propriamente ditos (entre a literatura em potência de ser re-editada, e o documento arquivístico), também em construção pelas leitoras e leitores escreviventes. Adentrar o espaço da tradição, em modo virtual, desvela a necessidade de discutirmos os usos dos arquivos pela (pós-)modernidade; e transitarmos por formas de arquivamento; extrapolando aquilo que os arquivos sempre conservaram, indo em direção ao que não guardavam, lançando, para isso, uma questão (antiga, pois já vinha sendo feita pelos movimentos negros, há mais de cem anos) à instituição e a seus arcontes.

Nos episódios narrados no diário de Carolina, viemos relacionando as preocupações/reflexões de Carolina sobre literatura e vida literária (esta como potência, já que ainda, no momento da escrita, estava em realização). As narrações sobre a vida, são, também, sobre-vida, que é o ponto de similitude com a recepção (parte como fobia/fetiche), que é a primeira leva de leitores, que não acompanharam a produção pós Quarto de despejo, e que não perceberam (ou não se importaram) com outros tantos tecidos que a autora teceu; e outras leitoras e leitores, que, reforçados pelo reconhecer o viver (vida e literatura), perceberam nos escritos de Carolina, "escrevivência de nós", o que pode ser lida, segundo Roseane Borges (2020), de modo bastante interessante e importante, também como arquivo.

No caso do texto literário, aceitar as primeiras leituras, os primeiros interesses sobre o texto de Carolina é fixar o jogo de sua literatura em uma construção estereotípica, 
lembrando que, para Bhabha (2013), essa construção é estratégica de domínio sobre os sujeitos que são a marca da diferença; recuperando valores que oscilam em um estratagema discursivo de ambivalência (esquizofrênica?) de prazer/repulsa; fobia/fetiche; fascínio/medo, que precisam ser sempre reiteradamente, reforçado, repetido para continuar valendo como estereótipo. Nessa direção, as transgressões do texto de Carolina foram, para o celebratório conservador que aponta nos textos "desvios" gramaticais, os ditos afastamentos da norma culta, que ainda oscilam nesse diapasão ambivalente, de apontar o erro diante das normas, em apontar o conserto em face dessas normas, e não sendo, pois, percebidas como uma concepção e realização de uma linguagem reexistente. E a ideia de "erro" grassa pela sociedade, recordemos a passagem dos cadernos quando uma pessoa a vê escrevendo, e a pergunta o que ela fazia; e, ao saber que Carolina escrevia literatura, essa pessoa emenda: "— Escreve e depois dá a um crítico para fazer a revisão." (JESUS, 1960, p. 20).

Se por um lado, ao texto como documento não se revisa pelo modelo da gramática, com um sentido científico para isso; ao texto literário, sua edição, contempla-se revisão, vinculada (ou vinculáveis) seja a uma ideia de normatização geral, para uma pretensa duração de sua inteligibilidade, mesmo a despeito da diversidade viva de tantas variantes re-existentes, seja, por meio disso também, alargado por um mito lusófono, de uma língua reinol cujas normas ora nos fazem masoquistamente padecer por não conhecê-las bem, ora sadicamente no prazer de condenar um semelhante por ignorá-las (não pasmemos que na história literária brasileira possa existir, a depender da autoria, uma qualidade literária fundada fortemente apenas no conhecer bem as normas). Tais condicionantes condicionavam, até então, o texto caroliniano a um lugar já dado pelos estereótipos que se constrói sobre a margem e seus sujeitos. Respeito ao texto em editá-lo como são editados todos os textos literários, preparados os originais, em ciência do expressamente escrito em momentos, pela autoria, que assim desejava ser publicada, revisada; respeito ao conselho editorial formado por especialistas negras, que leram também o expresso distendido por toda a obra: revisa-se; diagrama-se; e publica-se, qual fora o "novo" jeito de publicar textos, ao publicar Carolina?

Outros modos de reforçar e repetir estão dados pelas leituras que veem apenas aspectos negativos da vida, das histórias (seja como fetiche), desobservando a complexidade do que Carolina escreveu em sua inteireza das impressões (ainda que fragmentado, como é característico nos diários). Ela, em seus textos, tratou de diversos temas e questões, possibilitando, para eles, outras visibilidades, que se relacionam com nosso contemporâneo, como: Política (Práxis; sujeitos; repetições/recorrências; eleições etc.); da Ética e Moral(idade); das Instituições (Delegacia, hospital, prisão, escola etc.); das Questões étnico-raciais; da Infância, juventude; dos Lugares sociais; dos Trânsitos; Espaços da cidade; Violências; dos Corpos e Sexualidade; do Amor; sobre a Maternidade; a Solidão; o Suicídio; as Drogas (o álcool como um problema social). Falou sobre Direitos; sobre o Trabalho e a Moradia. Isso estruturado pela consciência política, da negritude, de 
classe.

Carolina afirmou sua identidade, como mulher negra, em sua afirmação literária, perceptível tanto pela boca da narradora, isto é, seus escritos, quanto pelo que a autoranarradora produziu, sob perspectivas: "Os bons eu enalteço, os maus eu critico. Devo reservar as palavras suaves para os operários, para os mendigos, que são escravos da miséria." (JESUS, 1960, p. 54). Da condição de sobrevivente, nessa sobrevida, que é resulto de uma estratégia de dominação, como condição de vida posta, por políticas excludentes aos sujeitos das minorias, percebemos, no texto, o que ela sempre frisou e há querido despontar, sua qualidade de escritora/ficcionista: atando vida, literatura e vida literária. Elaborando uma conexão entre as passagens sobre os atos de ler e escrever, vemos que, além da obviedade de que escritoras/es se constroem pelo ato da leitura, essa leitura se dá, primeiro, pela escuta da palavra, proferida pelos mais velhos, no caso de Carolina, pelo seu avô, senhor Benedito José da Silva, depois, pela "escuta" da palavra escrita. Nessas passagens ela registra isso e nos mostra que no caminho da sobrevivência, entre a lida diária para buscar água e conquistar o pão (frequentemente o mote de visadas acadêmicas), está a vivência na e para a linguagem, para a linguagem literária.

A autora escreve em seu livro em diversos momentos suas preferências e frequências de leitura e escrita. Nesses relatos, ela revela o esforço para vencer barreiras relacionadas ao acesso aos modos de produzir, publicar e fazer circular livros. Destacamos algumas passagens, em fragmentos do livro Quarto de despejo, em que a autora reitera sua relação com a palavra, lida e escrita, e esforços para suas realizações. A operação aqui, de seleção, dentro do que criticamos antes ser o selecionado (até, então, um selecionável), apresentamos não pelo desejo da leitura e escrita, nas revelações distendidas na escritura dos dias, mas para vemos como que, para Carolina, literatura e vida se imiscuem nos relatos, linguagem como vida, metalinguagem sendo, pois, o relato sobre a vida, para além da re-conhecida escrita sobre sobrevida.

Deixei o leito as 4 horas para escrever. Abri a porta e contemplei o céu estrelado. Quando o astro-rei começou despontar eu fui buscar água. Tive sorte! As mulheres não estavam na torneira. Enchi minha lata e zarpei. (20 de julho de 1955). [Diminuição no descanso para caber a escrita]. (1960, p. 18).

Quando fico nervosa [com implicância das vizinhas] não gosto de discutir. Prefiro escrever. Todos os dias eu escrevo. Sento no quintal e escrevo. (20 de julho de 1955). [Preferência e frequência da escrita]. (1960, p. 19).

...Eu gosto de ficar dentro de casa, com as portas fechadas. Não gosto de ficar nas esquinas conversando. Gosto de ficar sozinha e lendo. Ou escrevendo! (22 de julho de 1955). [Gosto pela leitura, pela escrita]. (1960, p. 23).

Seu João quis saber o que eu escrevia. Eu disse ser o meu diário. — Nunca vi uma preta gostar tanto de livros como você. Todos têm um ideal. O meu é gostar de ler. (23 de julho de 1955). [Sobre racismo diário, e o diário]. 
(1960, p. 23).

É que eu estou escrevendo um livro, para vendê-lo. Viso com esse dinheiro comprar um terreno para eu sair da favela. (27 de julho de 1955). [Motivação para a escrita de um livro]. (1960, p. 25).

- Não, meu filho. A democracia está perdendo os seus adeptos. No nosso país tudo está enfraquecendo. O dinheiro é fraco. A democracia é fraca e os políticos fraquíssimos. E tudo que está fraco, morre um dia. ...Os políticos sabem que eu sou poetisa. E que o poeta enfrenta a morte quando vê o seu povo oprimido. (20 de maio de 1958). [Leitura do contexto, práxis do poeta]. (1960, p. 35).

Estou desorientada, sem saber o que iniciar. Quero escrever, quero trabalhar, quero lavar roupa. Estou com frio. E não tenho sapato para calçar. Os sapatos dos meninos estão furados. (28 de maio de 1958). [Reorganização das ações da casa, ao que se inclui a escrita]. (1960, p. 40).

Quando vejo meus filhos comendo arroz e feijão, o alimento que não está ao alcance do favelado, fico sorrindo atoa. Como se eu estivesse assistindo um espetáculo deslumbrante. Lavei as roupas e o barracão. Agora vou ler e escrever. (1 de junho de 1958). [Relato feliz sobre o dia, para iniciar a leitura e a escrita]. (1960, p. 44).

Eu deixei o leito as 3 da manhã porque quando a gente perde o sono começa pensar nas misérias que nos rodeia. (...) Deixei o leito para escrever. Enquanto escrevo vou pensando que resido num castelo cor de ouro que reluz na luz do sol. Que as janelas são de prata e as luzes de brilhantes. Que a minha vista circula no jardim e eu contemplo as flores de todas as qualidades. (...) E preciso criar este ambiente de fantasia, para esquecer que estou na favela. (12 de junho de 1958). [Escrita e fantasia para se deslocar até o mundo criado e esquecer do ambiente precário em que vive]. (1960, p. 52).

...Eu escrevia peças e apresentava aos diretores de circos. Eles me respondiam: - É pena você ser preta. (16 de junho de 1958). [Escrita e divulgação do texto; resposta em enunciado racista, cuja significação expandida é dito que textos não podem ser escritos por mulheres pretas]. (1960, p. 58).

Deixei o leito as 5 e meia. Já estava cansada de escrever e com sono. Mas aqui na favela não se pode dormir, porque os barracões são úmidos, e a Neide tosse muito, e desperta-me. (11 de julho de 1958). [Sobre ambiente para Escrita]. (1960, p. 81).

...Hoje eu não lavo as roupas porque não tenho dinheiro para comprar sabão. Vou ler e escrever. (19 de julho de 1958). [Reposicionamento dos afazeres, leitura e escrita]. (1960, p. 85).

Um sapateiro perguntou-me se o meu livro é comunista. Respondi que é realista. Ele disse-me que não é aconselhável escrever a realidade. (9 de agosto de 1958). [Explicação sobre a matéria do livro]. (1960, p. 96).

...Lavei as louças e varri o barraco. Depois fui deitar. Escrevi um pouco. Senti sono, dormi. Acordei várias vezes na noite, com as pulgas que penetra 
nas nossas casas, sem convite. (23 de agosto de 1958). [A Escrita como parte do dia]. (1960, p. 104).

...Vocês já sabem que eu vou carregar água todos os dias. Agora eu vou modificar o início da narrativa diurna, isto é, o que ocorreu comigo durante o dia. (16 de outubro de 1958). [Interlocução em que afirmação de que mudaria o modo de relato]. (1960, p. 110).

Dei um banho nos filhos. Eles foram deitar-se. E eu fui lavar as louças. Depois fui escrever. Senti canseira e sono. Fui deitar. Matei umas pulgas que estava circulando na cama e deitei. E não vi mais nada. (3 de novembro de 1958). [A Escrita como parte do dia]. (1960, p. 116).

—Você não vai escrever? Não vai catar papel? Levanta para você escrever a vida dos outros. Eu levantei, peguei um pau de vassoura e fui falar-lhe para não me aborrecer que eu estou cansada de tanto trabalhar. (22 de julho de 1959). [Perguntas para si, em criar ânimo para levantar, para cuidar da casa, da cabeça, pela escrita]. (1960, p. 161).

...Eu fui escrever. Ninguém aborrece-me hoje. Quando o crepúsculo vinha surgindo, eu fui procurar a Vera. (28 de julho de 1959). [A Escrita como parte do dia]. (1960, p. 162).

...Escrevi até tarde, porque estou sem sono. Quando deitei adormeci logo e sonhei que estava noutra casa. E eu tinha tudo. Sacos de feijão. Eu olhava os sacos e sorria. Eu dizia para o João: -Agora podemos dar um ponta-pé na miséria. E gritei: - Vai embora, miséria! A Vera despertou-se e perguntou: Quem é que a senhora está mandando ir-se embora? (30 de julho de 1959). [A Escrita como parte do dia; e sonho]. (1960, p. 162).

...Passei a tarde escrevendo. Lavei todas as roupas. Hoje eu estou alegre. (16 de agosto de 1959). [A Escrita como parte do dia]. (1960, p. 167).

Para finalizar, recuperamos o que Conceição Evaristo falou em entrevista ao programa Nação, da TVE (2015), que, enquanto as classes abastadas leram o texto de fora para dentro, ela e outras tantas escritoras liam em identificação com a personagem: a sobrevivência, a fome era a sobrevivência e fome dessas leitoras; porque a vida e o esforço de escrita literária eram a vida e o esforço literário dessas escritoras; e é, pois, nesse sentido, que se elaboram as "escrevivências". Essas escritas, essas vidas escritas, escritas vivenciadas, sempre constituidoras de repertórios, palavras presentes, poéticas, têm constituído, ainda que não seja, de fato, o foco, outros arquivos, outras formas de arquivamento dos sujeitos, outros sujeitos, para além das formas possibilitadas/forjadas pelos Estados coloniais.

E, mesmo sob o perigo, alertado por Fanon (apud BHABHA, 2013, p. 31), de que, na afirmação das tradições nativas e na recuperação das histórias que foram reprimidas, se caia na fixidez e no fetichismo identitários, cujos movimento são o de lançar (ingenuamente) âncora no "romanceiro celebratório do passado", ou numa "homogeneização da história do presente"; as produções são novas; isto é, não partem de um continuum entre passado e presente, mas criam um outro "ato insurgente", que não é a recuperação "do passado como 
causa social ou precedente estético" (BHABHA, 2013, p. 29), mas que, ao renovar esse passado, (percebendo a opressão como regra, como dissera Benjamin (1994, em suas teses) poderíamos interromper a marcha atual do presente e suas ideias para o que seja o tal "progresso".

Novos "arquivos afro-brasileiros", evidenciam epistemes, culturas, sensibilidades, poéticas, linguagens, e engendram "nós" (TANUS, 2018), que se dão pelas redes de sociabilidades (da recepção, por olhos e ouvidos, razão e corporeidade; à produção, entre obras em todas fontes e tipos). Esses "nós", pronominais de comunidade, a qual Carolina pertence e para qual seus escritos têm se diferenciado, no sentido de revelação das substâncias portadoras, aos "nós", como embaraços; estes, observáveis em vários tempos e espaços, por conta também do que os textos carolinianos, e outros, tornam visíveis, e são, inclusive, perceptíveis, nos acervos aos quais Carolina se faz presente, com seus documentos, e textos literários.

A estes acervos da tradição - como expressões do domínio, entre formas e intenções diferenciais de arquivamento dos sujeitos e culturas (em apresentação dos modelos, como norma oficial; ao exemplo "desviante", este que informa a condição de sua irrepetibilidade, sob pena de retaliações, seja pela simples reprovação, às penas capitais) - foram incorporados os acervos de Carolina (no plural, mesmo, por sua múltipla forma, real e virtual; disperso entre várias instituições), que se apresentam e reapresentam-se, ausência, e lacuna, presença, opulência; como uma suplementação, em noção derridiana, de uma adição (que não sendo requisitada, supre uma falta do lado do significado, e influencia todo o sistema); constituindo e sendo constituída de tantos nós entre a representação/representatividade, e tantos de nós, como construção de comunidade; este antigo pronome novo, pelo qual deveremos repensar todos os arquivos da colonialidade.

Sobre um desses fios de alinhavo, destacamos esse novo em uma recepção, que cuidou de não cair nas armadilhas alertadas por Fanon (2008), que se apresentou nas cartas pela escritora antilhana Françoise Ega (2021) - $1^{a}$ edição francesa em 1978. Ela, imigrante em França, após ela ter lido um texto na revista "Paris Match" sobre Carolina de Jesus, rapidamente se identificara com Carolina, por serem mulheres, à margem da sociedade, negras, trabalhando como empregadas domésticas. Assim, naquele tempo, Françoise passou a escrever "cartas", que jamais foram entregues à Carolina. Nessas cartas ela relatou seu cotidiano laboral, descreveu o desrespeito sofrido por conta do preconceito das "patroas", além de relatar todas as dificuldades e das injustiças nas relações sociais. Françoise foi, por conta dos diários de Carolina, se conscientizando e iniciou uma luta pelos direitos; tendo falecido em 1976, aos 56 anos, um ano antes do falecimento de Carolina.

Outra carta, do epistolário afro-diaspórico ${ }^{6}$, relacionada à Carolina, foi escrita pela

\footnotetext{
${ }^{6}$ Lembramos aqui o projeto Cartas negras, que surgiu na década de 1990, como uma ideia de troca de cartas entre as escritoras Miriam Alves, Lia Vieira, Esmeralda Ribeiro, Sonia Fátima da Conceição, Geni Guimarães e Conceição Evaristo, como formação de um grupo de "vozes-mulheres" que discutiriam projetos de vida e de literatura. Desejavam a criação de um coletivo de escritoras negras em cuja reunião (associação de
} 
intelectual e escritora Cidinha da Silva, nestes tempos de pandemia da COVID-19. Nessa carta, intitulada "A Travessia no Barco da Coragem - Uma Carta à Carolina de Jesus" (2020), realizou-se um diálogo entre escritoras, em que a mais nova se referiu à mais velha, numa rede de reconhecimento da ancestralidade, de cumplicidade, de afetividade, de sororidade, de aprendizado, contando sobre suas batalhas do dia a dia, formativas, seus sucessos como mãe, estudante, crítica, intelectual, escritora. A jovem escritora termina dizendo que, ao escrever à Carolina, ela vai exercitando a "literatura possível", e diz para que Carolina lembrar de "dizer o que [...] acha das minhas tentativas de criar figuras de linguagem, seu olhar arguto e sensível é muito importante para mim" (SILVA, 2020, n.p.). Sobre vida, literatura, vida literária, Carolina "escrevive" nas redes intergeracionais, de mulheres escreviventes, que re-apresentam os "nós" e os enredamentos, possíveis, indispensáveis.

\section{Referências}

ARRUDA, Aline Alves. Carolina Maria de Jesus: Projeto Literário e Edição Crítica de um Romance Inédito. 257 f. Tese (Doutorado em Estudos Literários) - Faculdade de Letras, Universidade Federal de Minas Gerais, Belo Horizonte, 2015.

ASSIS, Machado de. Memorial de Aires. In: ASSIS, Machado de. Obra completa. v. I. 9 ed. Rio de Janeiro: Nova Aguilar, 1997, p. 1194-1293.

BENJAMIN, Walter. Sobre o conceito da história. In: BENJAMIN, Walter.Obras escolhidas I - magia e técnica, arte e política. 7. ed. Trad. de Sergio Paulo Rouanet. Prefácio de Jeanne Marie Gagnebin. São Paulo: Brasiliense, 1994. p. 222-232.

BHABHA, Hommi K. O local da cultura. Trad. de Myriam Ávila, Eliana Lourenço de Lima Reis e Gláucia Renate Gonçalves. Belo Horizonte: Editora UFMG, 2013.

BORGES, Roseane. Escrevivência em Conceição Evaristo: armazenamento e circulação dos saberes silenciados. In: DUARTE, Constância Lima; NUNES, Isabella Rosado. Escrevivência: a escrita de nós: reflexões sobre a obra de Conceição Evaristo. Ilustrações de Goya Lopes. Rio de Janeiro: Mina Comunicação e Arte, 2020. p. 182-205.

DALCASTAGNĖ, Regina. Literatura brasileira contemporânea: um território contestado. Vinhedo; Rio de Janeiro: Horizonte; Editora da Uerj, 2012.

DERRIDA, Jacques. Estou em guerra contra mim mesmo. Entrevista concedida em 18 ago. 2004 a Jean Birnbaum. Trad. de Edson Rosa da Silva. Margens/Márgenes, n. 5, p. 12-17, jul.-dez. 2004.

projetos intelectuais e literários) sugeririam a elaboração de formas e estratégias de estar no mundo, promovendo reflexões sobre questões que envolvem o ser mulher negra. No ano de 2017, Conceição retoma o projeto e convida as escritoras da nova geração: Ana Cruz, Ana Maria Gonçalves, Cristiane Sobral, Débora Garcia, Elizandra Souza, Jenyffer Nascimento, Lívia Natália, Mel Adún e Raquel Almeida. (TANUS; RODRIGUES, 2017). 
DERRIDA, Jacques. Mal de arquivo: uma impressão freudiana. Rio de Janeiro: Dumará, 2001.

DOSSE, François. El arte de la biografia: entre historia y ficción. México, DF: Universidad Iberoamericana, 2007.

EGA, Françoise. Cartas a uma negra. Capa por Violaine Cadinot; Trad. de Vinícius Carneiro e Mathilde Moaty. São Paulo: Todavia, 2021.

EVARISTO, Conceição. A escrevivência e seus subtextos. In: DUARTE, Constância Lima; NUNES, Isabella Rosado. Escrevivência: a escrita de nós: reflexões sobre a obra de Conceição Evaristo. Ilustrações de Goya Lopes. Rio de Janeiro: Mina Comunicação e Arte, 2020. p. 26-47.

EVARISTO, Conceição. Da grafia-desenho de minha mãe, um dos lugares de nascimento de minha escrita. In: ALEXANDRE, Marcos Antônio (Org.) Representações performáticas brasileiras: teorias, práticas e suas interfaces. Belo Horizonte: Mazza, 2007. p. 17-21.

FANON, Frantz. Pele negra, máscaras brancas. Trad. de Renato da Silveira. Prefácio de Lewis R. Gordon Salvador: EDUFBA, 2008.

FARIAS, Tom. Carolina: uma biografia. Rio de Janeiro: Malê, 2018.

FERNANDEZ, Raffaela Andréa. Processo criativo nos manuscritos do espólio literário de Carolina Maria de Jesus. Tese (Doutorado em Teoria e História Literária) - Universidade Estadual de Campinas, Campinas, 2015.

FOUCAULT, Michel. A arqueologia do saber. Trad. de Luis Felipe Baeta Neves. 7. ed. Rio de Janeiro: Forense Universitára: 2008.

FREIRE, Paulo. Pedagogia do oprimido. 60. ed. Rio de Janeiro: Paz e Terra, 2016.

IBICT. Instituto Brasileiro de Informação em Ciência e Tecnologia. Disponível em: https://bdtd.ibict.br/. Acesso em: 28 mar. 2021.

JESUS, Carolina Maria de. Anexo I. Alguns conceitos e faces do poeta, segundo Carolina [22 de maio de 1958]. In: PERPÉTUA, Elzira Divina. A vida escrita de Carolina de Jesus. Belo Horizonte: Nandyala, 2014.

JESUS, Carolina Maria de. Onde estaes Felicidade? Organizado por Dinha e Raffaella Fernandez. São Paulo: Me Parió Revolução, 2014.

JESUS, Carolina Maria de. Quarto de despejo: Diário de Uma Favelada. São Paulo: Ática, 2014.

JESUS, José Carlos de. Entrevista. 27 jun. 1992. In: LEVINE, Robert; MEIHY, José Carlos Sebe Bom. The Life and Death of Carolina Maria de Jesus. USA: University of New Mexico press, 1995. p. 115-125.

LEVINE, Robert; MEIHY, José Carlos Sebe Bom. The Life and Death of Carolina Maria de Jesus. USA: University of New Mexico press, 1995. 
MARQUES, Reinaldo. Arquivos literários, entre o público e o privado. Lo que los archivos cuentan, v.3, p. 17-62, 2014.

MBEMBE, Achille. Crítica da razão negra. Lisboa: Antígona, 2014.

MEIHY, José Carlos Sebe Bom. Longe da sala de visitas - centenário Carolina Maria de Jesus. Estado de Minas, Caderno Pensar, p. 1 e 3, 17 maio 2014.

MIRANDA, Fernanda Rodrigues de. Os caminhos literários de Carolina Maria de Jesus: experiência marginal e construção estética. Dissertação (Mestrado em Letras) - Faculdade de Filosofia, Letras e Ciências Humanas, Universidade de São Paulo, 2013.

OLIVEIRA, Acauam. 20 anos de "Sobrevivendo no inferno". Entrevista. Blogbvps, 09 jul. 2019. Disponível em: https://blogbvps.wordpress.com/2019/07/09/20-anos-desobrevivendo-no-inferno-entrevista-com-acauam-oliveira-upe/\#_ednref1. Acesso em: 25 mar. 2021.

OLIVEIRA, Flávia Figueiredo de. A literatura afro-brasileira de autoria de mulheres nos acervos das Bibliotecas Públicas do Brasil. 85 f. il. Monografia (Graduação em Biblioteconomia) - Universidade Federal do Rio Grande do Norte, Centro de Ciências Sociais Aplicadas, Graduação em Biblioteconomia. Natal, RN, 2020.

PERPÉTUA, Elzira Divina. A vida escrita de Carolina de Jesus. Belo Horizonte: Nandyala, 2014a.

PERPÉTUA, Elzira Divina. A proposta estética em Quarto de despejo, de Carolina de Jesus. Scripta, Belo Horizonte, v. 18, n. 35, p. 255-266, $2^{\circ}$ sem. 2014 b.

SILVA, Cidinha da. A Travessia no Barco da Coragem - Uma Carta à Carolina de Jesus. Jornalistas livres, 20 jul. 2020. Disponível em: https://jornalistaslivres.org/a-travessia-nobarco-da-coragem-uma-carta-a-carolina-de-jesus/. Acesso em: 21 jul. 2020.

SILVA, TC. Movimento quilombola. \#PalavrasCruzadas: Lugares de Fala Contemporâneos, Sesc Vila Mariana, 13 jul. 2020. Disponível em: https://www.youtube.com/watch?v=AZHuj2Ap3Q. Acesso em: 01 mar. 2021.

SOUZA, Gustavo Tanus C. de. Constelações de poeta negro: imagens de Adão Ventura no arquivo literário. Dissertação (Mestrado em Teoria da Literatura e Literatura Comparada) Universidade Federal de Minas Gerais, Belo Horizonte, 2017.

TANUS, Gustavo. Unpacking the boxes of Adão Ventura's archive: reflections on the black poet in the literary archive. Archival Science, v. 19, n. 1, p. 51-70, 2019.

TANUS, Gustavo. Entre nós, a representação e a representatividade: imagens, literatura e arquivo afro-brasileiros. In: OLIVEIRA, Aciomar; COSTA, Antonio Carlos (Org.). Relações étnicas: conexões possíveis. Ibirité, MG: Poesias Escolhidas Editora, 2018, v. 1, p. 115126.

TANUS, Gustavo; RODRIGUES, Thamyris. Cartas negras: notícias da escrevivência, projetos de vida, projetos literários. literafro, Belo Horizonte, 29 nov. 2017. Disponível em: https://bit.ly/3rBRXKw. Acesso em: 03 mar. 2021. 
TVE. Carolina Maria de Jesus. Programa Nação. 18 set. 2015. Disponível em: https://www.youtube.com/watch?v=E5V8SvEN2II. Acesso em: 26 set. 2015.

\section{NOTAS DE AUTORIA}

Gustavo Tanus (gustavotcs@gmail.com) é doutorando em Literatura Comparada pela Universidade Federal do Rio Grande do Norte. Mestre em Teoria da Literatura e Literatura Comparada, bacharel e licenciado em Português e bacharel em Edição pela Universidade Federal de Minas Gerais. Pesquisador e integrante da comissão editorial do literafro - portal da literatura afro-brasileira, Núcleo de Estudos Interdisciplinares da Alteridade da Universidade Federal de Minas Gerais (NEIA/UFMG).

\section{Agradecimentos}

Não se aplica.

\section{Como citar esse artigo de acordo com as normas da ABNT}

TANUS, Gustavo. Impressões e arquivos: notas sobre-vida, literatura e vida literária em Quarto de Despejo, de Carolina Maria de Jesus. Anuário de Literatura, Florianópolis, v. 27, p. 01-19, 2022.

\section{Contribuição de autoria \\ Não se aplica.}

\section{Financiamento}

O presente trabalho foi realizado com apoio da Coordenação de Aperfeiçoamento de Pessoal de Nível Superior - Brasil (CAPES) - Código de Financiamento 001.

\section{Consentimento de uso de imagem}

Não se aplica.

\section{Aprovação de comitê de ética em pesquisa}

Não se aplica.

\section{Conflito de interesses}

Não se aplica.

\section{Licença de uso \\ Os/as autores/as cedem à Revista Anuário de Literatura os direitos exclusivos de primeira publicação, com o trabalho simultaneamente licenciado sob a Licença Creative Commons Attribution (CC BY) 4.0 International. Estra licença permite que terceiros remixem, adaptem e criem a partir do trabalho publicado, atribuindo o devido crédito de autoria e publicação inicial neste periódico. Os autores têm autorização para assumir contratos adicionais separadamente, para distribuição não exclusiva da versão do trabalho publicada neste periódico (ex.: publicar em repositório institucional, em site pessoal, publicar uma tradução, ou como capítulo de livro), com reconhecimento de autoria e publicação inicial neste periódico.}

\section{Publisher}

Universidade Federal de Santa Catarina. Programa de Pós-graduação em Literatura. Publicação no Portal de Periódicos UFSC. As ideias expressadas neste artigo são de responsabilidade de seus/suas autores/as, não representando, necessariamente, a opinião dos/as editores/as ou da universidade.

\section{Histórico}

Recebido em: 20/05//2021

Aprovado em: 12/11/2021

Publicado em: 21/02/2022 